\title{
Tricyclic Antidepressant-Induced Anticholinergic Delirium in a Young Healthy Male Individual
}

\author{
Matthew King ${ }^{1}$ (1) Nauman Ashraf ${ }^{2,3,4}$
}

Published online: 2 January 2018

(C) The Author(s) 2018. This article is an open access publication

\begin{abstract}
The tricyclic antidepressants, while older, still have their place in the treatment of depression today. They are efficacious but less selective and thus have the potential of eliciting many side effects. Anticholinergic delirium is a potential complication when using a tricyclic antidepressant or other anticholinergic agent. Following the Naranjo algorithm, this case report describes a probable amitriptyline-induced delirium in a previously healthy, 36-year-old Caucasian male individual after he promptly resumed his nightly 200-mg amitriptyline dose, following abrupt discontinuation of the medication 1 week earlier. This case emphasizes the importance of drug titration/tapering and therapeutic drug monitoring of patients taking tricyclic antidepressants.
\end{abstract}

Matthew King

Medk87@gmail.com

1 Ozark Center, Freeman Hospital, Kansas City University of Medicine and Biosciences, 2002 Hampshire Terrace apt 2, Joplin, MO 64804, USA

2 Department of Behavioral Sciences, OSU-COM, Columbus, OH, USA

3 KCUMB Freeman, Joplin, MO, USA

4 Ozark Center, Joplin, MO, USA

\section{Key Points}

Delirium is a rare but potential consequence of taking a tricyclic antidepressant.

It is essential to recognize predisposing factors that may facilitate delirium in patients taking tricyclic antidepressants.

Drug titration/tapering and therapeutic drug monitoring should be used in patients taking tricyclic antidepressants.

\section{Introduction}

Over 600 compounds have anticholinergic properties, including prescription drugs, over-the-counter medications, and plants [1]. Most of these medications would be more accurately described as being antimuscarinic because they do not inhibit nicotinic receptors. The $\mathrm{M}_{1}$ muscarinic receptor blockade is responsible for reducing central acetylcholine and is implicated in delirium [2]. Peripheral M1 receptors, in addition to other muscarinic receptors such as $\mathrm{M}_{2}, \mathrm{M}_{3}$, and $\mathrm{M}_{4}$, when blocked, can cause additional anticholinergic symptoms such as constipation, blurred vision, dry mouth, and urinary retention. Tricyclic antidepressants (TCAs), in addition to blocking muscarinic receptors, also block norepinephrine and serotonin reuptake (improving depression) and affect many other receptors including $\mathrm{H}_{1}$-histamine (weight gain and drowsiness), $\alpha_{1}$-adrenergic (dizziness, drowsiness, decreased blood 
pressure), and voltage-sensitive sodium channels (arrhythmias). There may also be some additional antagonistic effects at the serotonin $2 \mathrm{~A}$ and $2 \mathrm{C}$ receptors (improving depression and sleep) [3].

As a result of central antimuscarinic activity, anticholinergic delirium is a potential complication when using a TCA such as amitriptyline or another anticholinergic agent [4]. The summary of product characteristics for the TCA amitriptyline shows confusion, delusions, hallucinations, and hypomania as potential central nervous system complications [5]. Previous cases of delirium associated with anticholinergic drugs, including TCAs, have been documented in the literature but of the populations affected, the elderly are at the greatest risk [4, 6]. Elderly patients are speculated to be at higher risk because of physiological and pathophysiological changes that accompany the aging process. For example, it has been shown that muscarinic receptors, which are implicated in delirium, may be more sensitive in elderly people. In addition, the use of multiple drugs is more common among the elderly, which may result in pharmacodynamic and pharmacokinetic drug interactions that heighten anticholinergic effects [7].

Tricyclic antidepressants, including amitriptyline, are no longer first line in the treatment of depression because of the development of more selective and safer agents such as the selective serotonin reuptake inhibitors. However, amitriptyline still has its place in the treatment of depression and off-label uses including treatment of post-herpetic neuralgia, migraine prophylaxis, and bulimia. Therapeutic drug monitoring is particularly useful with TCAs because of their potential toxicity and variable metabolism within a population. Amitriptyline is metabolized mainly by the cytochrome P450 (CYP)2C19 and CYP2D6 pathways. An individual's pharmacogenetics can significantly alter the amount of plasma TCA concentration even when taking normal doses [8]. In 2016, the Clinical Pharmacogenetics Implementation Consortium made dosing recommendations for TCAs based on CYP2C19 and CYP2D6 genotypes [9].

The central nervous system and cardiac effects from TCA poisoning can be fatal and thus monitoring for toxicity as well as symptom improvement is important. Tricyclic antidepressant toxicity will occur in about $5 \%$ of the population taking a standard dose without adjustment from therapeutic drug monitoring [10]. To avoid toxicity, patients should be started on a lower dose and titrated up over the course of several days. This case report details a probable amitriptyline-induced delirium in a 36-year-old Caucasian male individual, after he had promptly resumed his 200-mg evening dose of amitriptyline, despite abrupt discontinuation 1 week prior.

\section{Case Presentation}

A 36-year-old Caucasian male individual awoke suddenly at about 23:00, $1 \mathrm{~h}$ after taking a 200-mg dose of amitriptyline. The patient's wife, who was also in the bedroom at the time, was alarmed to see the patient suddenly rise from bed and disrobe for no apparent reason. When asked what he was doing, the patient replied that he needed to get ready for work. As the patient had just recently switched to working day shifts again, this did not make much sense but before his wife could question him, he dashed into the kitchen upon where he began pulling out pots and pans from a bottom cabinet. The patient's wife closely followed, demanding what was going on. Upon entering the kitchen, the patient explained in quick but articulate speech that he had to repair the pots and pans before work started.

No sooner had his wife inquired as to what was wrong with the pots and pans that necessitated their repair so late at night, the patient dashed back into the bedroom where he reportedly began digging through dresser drawers in search of cereal and milk. At this point, the patient's wife became concerned enough to call the police, but before their arrival, the patient was able to dress himself for work, have a conversation with the bedroom curtains as if they were his coworkers and finally, he attempted to crawl out the upperstory bedroom window in an attempt to get to his car so he could drive to work.

The patient stated he had no recollection of these events but did remember becoming quite upset and irritable with the police because he was under the impression that they had arrived extremely early in the morning for no apparent reason. The patient denied recollection of the actual conversation between the police and himself but does remember they took him to jail shortly after their arrival. The patient had received a warrant for his arrest owing to an unpaid ticket for not wearing a seatbelt. He was able to remember that he became extremely tired upon arrival to jail and subsequently slept until morning; upon where he awoke his usual self.

The patient denied ever having an episode like this in the past. He had presented to his primary care nurse practitioner 2 months earlier for trouble sleeping secondary to racing thoughts. The patient had a history of chronic unspecified depression and anxiety, which were not being treated at the time. He was placed on brexpiprazole (Rexulti ${ }^{\circledR}$ is co-manufactured by Otsuka Pharmaceutical Co., Ltd., Chiyoda, Tokyo, Japan and H. Lundbeck A/S, Copenhagen, Denmark) $2 \mathrm{mg}$ daily, along with amitriptyline 100-200 mg at night for depression and sleep, as well as metoprolol $25 \mathrm{mg}$ twice daily for anxiety. He had no other medical history and took no other medications. The patient did admit to occasional marijuana use but advised he had not used marijuana for 2 days before the incident. 
The patient states he was told to start with $100 \mathrm{mg}$ of amitriptyline at night and to take a second 100-mg tablet if it did not seem to be working. He reports that he began taking $200 \mathrm{mg}$ of amitriptyline every night about a week after being on the 100-mg dose. He asserted it was effective as he was able to get about $6 \mathrm{~h}$ of sleep per night with the 200-mg dose compared with the 100-mg dose where he was averaging only 3-4 h of sleep. The patient continued his medication regime for 7 weeks; at which point he was switched from day to night shifts at work. He discontinued his evening dose of amitriptyline and reported having tried to take the amitriptyline in the morning instead but found it to be too sedating as he seemed to be sleeping most of the day. The patient subsequently stopped taking his amitriptyline over the next 7 days as he seemed to be getting adequate sleep during the day without it. After the following weekend and upon resuming his normal work schedule that Monday, the patient took his previous 200-mg amitriptyline dose at night before going to bed. Approximately an hour later, the events described above transpired.

\section{Discussion}

This case illustrates a probable amitriptyline-induced delirium in a 36-year-old male individual, after he promptly resumed his 200-mg dose, despite abrupt cessation of the medication 1 week earlier. Following the Naranjo algorithm, a score of 6 was calculated for a drug reaction to amitriptyline. A score of 0 indicates a doubtful adverse drug reaction. A score of 1-4 indicates a possible adverse drug reaction. A score of 5-8 indicates a probable drug reaction and a score above or equal to 9 indicates a definite adverse drug reaction.

The drug was scored as follows; $(+1)$ for there being previous conclusive reports on amitriptyline causing delirium, $(+2)$ for the adverse event appearing after the suspected drug was given, $(+1)$ for the adverse reaction improving when the drug was discontinued, $(+0)$ for not being able to observe a repeat episode of delirium as the drug was discontinued, $(+2)$ for there not being other causes that could exclusively account for the patient's delirious episode, $(+0)$ for there not being a placebo given to test against amitriptyline for the onset of the patient's delirium, $(+0)$ for being unable to test for drug concentrations in the patient's serum, $(+0)$ for it being unknown if the drug reaction was more severe when the dose was increased and less severe when the dose was decreased (although it could be argued for $\mathrm{a}+1$ because the patient did not experience symptoms when titrated up to his 200-mg dose of amitriptyline vs. the onset of symptoms when starting abruptly at $200 \mathrm{mg}$ without titration), $(+0)$ for the patient not having a delirious reaction to similar drugs in the past (the patient had never taken a TCA previously), and $(+0)$ for the adverse event being subjective and the inability to confirm with objective evidence.

When using Epocretes.com to look for cross-reactions of the medications that he was taking (brexpiprazole, metoprolol, and amitriptyline), no significant interaction could be found that could explain the patient's delirious episode except that of seizure. Other drug interactions found included hyperthermia, hyperglycemia, hypotension, central nervous system depression, and psychomotor impairment. Despite the patient discontinuing amitriptyline, he continued to take his normal daily dose of brexpiprazole. It is worth noting that although brexpiprazole mainly binds to serotonin, dopamine, and noradrenergic receptors, it also exhibits affinity for muscarinic M1 receptors [11]. While the patient had no interruptions in taking the brexpiprazole and experienced no side effects even while taking it along with the amitriptyline for 7 weeks, it is plausible that it could have played a role in predisposing the patient to delirium by participating in the blockade of central muscarinic receptors.

Brexpiprazole and amitriptyline are both known to lower the seizure threshold $[11,12]$. Furthermore, it may be difficult to differentiate a seizure from a delirious cause of agitation and altered mental status. This is particularly true in patients who are prone to both seizures and delirium. Complex partial seizures, whether repeated or prolonged, can result in marked agitation, at times with hypomania, hallucinations, illusions, and religiosity [13]. During the postictal or interictal periods, there can occasionally be acute psychosis in subjects without a prior psychiatric history. Left-sided brain foci have been associated with dysphoria, while right-sided discharges have been associated with laughter and hypomania [13, 14]. Given that the patient had no prior history of seizures and the onset of delirium was an hour after taking the amitriptyline, the patient's symptoms are more consistent with the Diagnostic and Statistical Manual of Mental Disorders, Fifth Edition criteria for a medication-induced delirium; however, a complex partial seizure cannot be completely ruled out [15].

While the pharmacogenetics of the patient are not known, they could have potentially altered the plasma amitriptyline concentration [8]. Cytochrome P450 enzymes are essential for the metabolism of many medications and can show significant variability between people and race. For example, Martis et al. [16]. found that based on observed genotypes for the CYP2C19 alleles, African American, Asian, Caucasian, and Hispanic individuals and Ashkenazi Jews were able to be classified as ultra-rapid (3, $2,3,2,4 \%$, ) extensive $(59,42,72,71,67 \%)$, intermediate $(19,44,18,18 \%, 18 \%)$, and poor $(5,8,4,2,4 \%)$ 
metabolizers, respectively. In 2016, the Clinical Pharmacogenetics Implementation Consortium made dosing recommendations for TCAs based on CYP2C19 and CYP2D6 genotypes [8]. The average half-life of amitriptyline is 10-26 h [17]. Therefore, the patient would have most likely cleared the drug from his system during the week interval where he was not taking it. If the patient were to have a slower metabolism of the drug that caused it to build up to toxic concentrations, one would expect that the patient would also have shown signs of toxicity while consecutively taking his 200-mg dose. Amitriptyline is readily absorbed from the gastrointestinal tract and peak plasma concentrations occur within approximately $6 \mathrm{~h}$ of oral administration [5]. The patient was reportedly symptomatic within an hour after taking his 200-mg dose. While TCAs are anticholinergic agents, they are also strong antihistamines and TCA-poisoned patients are more likely to be sedated than delirious [18]. This would seem to explain why the patient became more lethargic and fatigued rather than having increased or prolonged delirium as time went on.

The patient did report a history of substance abuse, specifically smoking marijuana, that he used to self-treat his anxiety and depression but denied additional recreational drug use. The marijuana that the patient reported using was not regulated and may have contained other substances. Although debated, there is evidence that tetrahydrocannabinols reduces the utilization of brain acetylcholine, which could produce or exacerbate anticholinergic symptoms [19]. This may be evidenced by the propensity of marijuana to cause anticholinergic-like effects such as dry mouth, tachycardia, and forgetfulness. Furthermore, the metabolic enzymes CYP2C9 and CYP2C19, described above, are known to be used in metabolizing marijuana; a potential avenue for drug interaction with amitriptyline [20].

The patient did however report that he had not used marijuana for 2 days prior to his presumed delirious episode. However, it is possible that there may have been residual anticholinergic effects that could have theoretically predisposed the patient to having a delirious episode but would have most likely been insufficient as an exclusive cause given the time lapse between drug use and onset of the patient's symptoms. Additionally, given that the patient had been smoking marijuana intermittently but consistently with brexpiprazole, it seems unlikely that an interaction between the marijuana and brexpiprazole alone would account for a sudden delirious state.

Another consideration would be an antidepressant-induced manic episode. The patient had a long-standing history of unspecified depression and a bipolar diagnosis could have been missed. However, the patient did not meet Diagnostic and Statistical Manual of Mental Disorders,
Fifth Edition criteria for manic or hypomanic episodes as an inpatient nor in terms of his clinical history [21]. The abrupt onset of symptoms an hour after taking the amitriptyline and return to baseline within $12 \mathrm{~h}$ is more consistent with a drug-induced delirium [15].

\section{Conclusion}

While TCAs have the potential of causing an antimuscarinic delirium, it is most often observed in the geriatric population $[4,6]$. In fact, per STOPP criteria (Screening Tool of Older Persons' Potentially Inappropriate Prescriptions), TCAs and anticholinergic agents should be avoided in elderly patients when possible and other drug alternatives sought, in an attempt to reduce morbidity and mortality in this patient population [22]. Following the Naranjo algorithm, this case report describes a probable amitriptyline-induced delirium in a previously healthy, 36-year-old Caucasian male individual after he promptly resumed his nightly 200-mg amitriptyline dose, despite abruptly stopping the medication 1 week earlier. It is possible that the patient's concomitant brexpiprazole use, along with his marijuana use 2 days earlier, predisposed the patient to an amitriptyline-induced delirium. This case report highlights the importance of drug titration/tapering and therapeutic drug monitoring of patients while taking TCAs.

\section{Compliance with Ethical Standards}

Funding No financial support was received for the preparation of this manuscript.

Conflict of interest Matthew King and Nauman Ashraf have no conflicts of interest directly relevant to the content of this article.

Consent to participate The patient involved in the study provided verbal consent for the publication of this case report and any additional related information was taken from the patient in the presence of the senior author.

Open Access This article is distributed under the terms of the Creative Commons Attribution-NonCommercial 4.0 International License (http://creativecommons.org/licenses/by-nc/4.0/), which permits any noncommercial use, distribution, and reproduction in any medium, provided you give appropriate credit to the original author(s) and the source, provide a link to the Creative Commons license, and indicate if changes were made.

\section{References}

1. Su M, Goldman M. Anticholinergic poisoning. UpToDate ${ }^{\circledR}$. 2017. http://www.uptodate.com/contents/anticholinergicpoisoning. Accessed 26 Dec 2017.

2. Dawson AH, Buckley NA. Pharmacological management of anticholinergic delirium: theory, evidence and practice. Br J Clin Pharmacol. 2016;81(3):516-24. 
3. Stahl SM, Muntner N. Antidepressants/classic antidepressants: tricyclic antidepressants. In: Stahl SM, editor. Essential psychopharmacology: neuroscientific basis and practical application. Cambridge: Cambridge University Press; 2013. p. 342-6.

4. Karlsson I. Drugs that induce delirium. Dement Geriatr Cognit Disord. 1999;10(5):412-5.

5. Amitriptyline: summary of product characteristics. Electronic Medicines Compendium. https://www.medicines.org.uk/emc/. Accessed Sept 2017.

6. Alagiakrishnan K. An approach to drug induced delirium in the elderly. Postgrad Med J. 2004;80(945):388-93.

7. Feinberg M. The problems of anticholinergic adverse effects in older patients. Drugs Aging. 1993;3(4):335-48.

8. Dean L. Amitriptyline therapy and CYP2D6 and CYP2C19 genotype. In: Pratt V, McLeod H, Dean L, Malheiro A, Rubinstein W, editors. Medical genetics summaries [internet]. Bethesda: National Center for Biotechnology Information. 2017. http://www.ncbi.nlm.nih.gov/books/NBK425165/\#!po=0.746269. Accessed 26 Dec 2017.

9. Hicks JK, Swen JJ, Thorn CF, et al. Clinical pharmacogenetics implementation consortium guideline for CYP2D6 and CYP2C19 genotypes and dosing of tricyclic antidepressants. Clin Pharmacol Ther. 2013;93(5):402-8.

10. Preskorn SH, Dorey RC, Jerkovich GS, et al. Therapeutic drug monitoring of tricyclic antidepressants. Clin Chem. 1988;34(5):822-8.

11. Rexulti ${ }^{\circledR}$ : highlights of prescribing information. Rexulti ${ }^{\circledR}$ label, FDA. 2015. http://www.accessdata.fda.gov/drugsatfda_docs/ label/2015/205422s0001bl.pdf. Accessed 26 Dec 2017.

12. Presckorn SH, Fast GA. Tricyclic antidepressant-induced seizures and plasma drug concentration. J Clin Psychiatry. 1992;53(5):160-2.
13. Kaplan PW. Delirium and epilepsy. Dialogues Clin Neurosci. 2003;5(2):187-200.

14. Hurwitz TA, Wada JA, Kosaka BD, Strauss EH, et al. Cerebral organization of affect suggested by temporal lobe seizures. Neurology. 1985;35(9):1335-7.

15. Delirium. Diagnostic and statistical manual of mental disorders. 5th ed. Washington, DC: American Psychiatric Publishing; 2014. p. 596.

16. Martis S, Peter I, Hulot JS, Kornreich R, Desnick RJ, Scott SA. Multi-ethnic distribution of clinically relevant CYP2C genotypes and haplotypes. Pharmacogenom J. 2013;13(4):369-77.

17. Rogers HJ, Morrison PJ, Bradbrook ID, et al. The half-life of amitriptyline. Br J Clin Pharmacol. 1978;6(2):181-3.

18. Salhanick SD. Tricyclic antidepressant poisoning. KCUMB Library, UpToDate ${ }^{\circledR}$. 2016. http://www-uptodate-com.proxy. kcumb.edu:2443/contents/tricyclic-antidepressant-poisoning. Accessed 26 Dec 2017.

19. Cheney DL. Marijuana and cholinergic dynamics. 1981. https:// link.springer.com/chapter/10.1007/978-1-4684-8643-8_81. Accessed Sept 2017.

20. Stout SM, Cimino NM. Exogenous cannabinoids as substrates, inhibitors, and inducers of human drug metabolizing enzymes: a systematic review. Drug Metab Rev. 2014;46(1):86-95.

21. Bipolar and related disorders. Diagnostic and statistical manual of mental disorders. 5th ed. Washington, DC: American Psychiatric Publishing; 2014. p. 124.

22. Gallagher P, Ryan C, Byrne S, Kennedy J, O’Mahony D. STOPP (Screening Tool of Older Person's Prescriptions) and START (Screening Tool to Alert Doctors to Right Treatment): consensus validation. Int J Clin Pharmacol Ther. 2008;46(2):72-83. 